\title{
Innate lymphoid cells and allergic inflammation
}

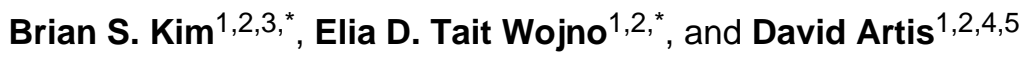 \\ ${ }^{1}$ Department of Microbiology, Perelman School of Medicine, University of Pennsylvania, \\ Philadelphia, PA 19104. \\ ${ }^{2}$ Institute for Immunology, Perelman School of Medicine, University of Pennsylvania, Philadelphia, \\ PA 19104. \\ ${ }^{3}$ Department of Dermatology, Perelman School of Medicine, University of Pennsylvania, \\ Philadelphia, PA 19104. \\ ${ }^{4}$ Department of Pathobiology, School of Veterinary Medicine, University of Pennsylvania, \\ Philadelphia, PA 19104.
}

\begin{abstract}
Group 2 innate lymphoid cells (ILC2s) play critical roles in anti-helminth immunity and airway epithelial repair. Recently, these cells have also emerged as key players in the development of allergic inflammation at multiple barrier surfaces. ILC2s arise from common lymphoid progenitors in the bone marrow, are dependent on the transcription factors RORa, GATA3 and TCF-1 and produce the type 2 cytokines IL-4, IL-5, IL-9 and/or IL-13. The epithelial cell-derived cytokines IL-25, IL-33 and TSLP regulate the activation and effector functions of ILC2s, and recent studies suggest that their responsiveness to these cytokines and other factors may depend on their tissue environment. In this review, we focus on recent advances in our understanding of how ILC2s are differentially regulated in the context of allergic inflammation and discuss the therapeutic potential of targeting ILC2s in the treatment of allergic diseases.
\end{abstract}

\section{Introduction}

Allergic diseases such as asthma, allergic rhinitis, atopic dermatitis (AD) and food allergy are driven by $T$ helper type $2\left(\mathrm{~T}_{\mathrm{H}} 2\right)$ cytokine responses characterized by the production of the cytokines interleukin (IL)-4, IL-5, IL-9 and IL-13. Exposure to environmental allergens at epithelial barrier surfaces induces epithelial cell-derived cytokine responses that promote dendritic cell activation, the development of $\mathrm{CD}^{+} \mathrm{T}_{\mathrm{H}} 2$ cell responses, antigen-specific $\operatorname{IgE}$ production and the recruitment of effector cell populations such as granulocytes to mucosal surfaces. Innate lymphoid type 2 cells (ILC2s) are a recently described subset of innate immune cells that also respond to epithelial cell-derived cytokines IL-25, IL-33 and thymic stromal lymphopoietin (TSLP) at mucosal and skin surfaces and produce the $\mathrm{T}_{\mathrm{H}} 2$ cellassociated cytokines IL-4, IL-5, IL-9 and IL-13. This review will focus on the recent

\footnotetext{
${ }^{5}$ Correspondence: Dr David Artis, Department of Microbiology, Institute for Immunology, Perelman School of Medicine, University of Pennsylvania, BRB II/III Room 356, 421 Curie Boulevard, Philadelphia, PA 19104, USA. dartis@mail.med.upenn.edu.

*These authors contributed equally to this publication
} 
advances in our understanding of how ILC2s contribute to the development of allergic inflammation at multiple barrier surfaces and how they may differentially respond to tissuespecific cytokines and factors. We highlight recent studies that reveal how ILC2s are regulated and discuss the therapeutic potential of targeting ILC2s in the context of allergic disease.

\section{Definition}

Innate lymphoid cells (ILCs) are part of a family of immune cells that are heterogeneous in their cytokine production profiles, transcription factor expression and effector functions [1,2]. ILCs do not express cell lineage markers associated with T cells, B cells, dendritic cells (DCs), macrophages and granulocytes, but express CD90 (Thy1 antigen), CD25 (IL-2Ra) and CD127 (IL-7Ra) [1]. These cells are derived from a common lymphoid progenitor, and their development is partially or wholly dependent on the common $\gamma$-chain ( $\gamma \mathrm{c}$ or CD132), IL-7, Notch and the transcription factor Inhibitor of DNA binding 2 (Id2) (Table 1) [3-6]. ILCs are currently categorized into three distinct populations based on their developmental requirements for defined transcription factors and their expression of cell surface markers and effector cytokines [1]: group 1 ILCs (ILC1s) include classical NK cells and T-bet-dependent IFN- $\gamma$-producing ILCs; RORa- [6,7], GATA3- [8,9] and TCF-1dependent [10] group 2 ILCs (ILC2s) produce IL-5, IL-9, IL-13 and/or amphiregulin[5]; and ROR $\gamma \mathrm{t}$-dependent group 3 ILCs (ILC3s) produce IL-17A and/or IL-22 [11]. These ILC groups are analogous to the previously described $\mathrm{T}_{\mathrm{H}} 1, \mathrm{~T}_{\mathrm{H}} 2$ and $\mathrm{T}_{\mathrm{H}} 17 \mathrm{CD} 4^{+} \mathrm{T}$ helper cell subsets. However, although ILCs appear to have parallel functions to adaptive $\mathrm{CD} 4^{+} \mathrm{T}$ cells, they are unique in that they respond to innate signals in the absence of antigen-specificity and have distinct phenotypic and functional profiles.

Although these cells are critical for protective immunity to helminth parasites in the intestine and lung epithelial repair in the context of influenza infection [5,12-14], ILC2s also appear to promote pathologic allergic inflammation at multiple barrier surfaces (Fig. 1).

Importantly, these cells have been implicated in the pathogenesis of a number of human allergic diseases such as asthma, allergic rhinitis and atopic dermatitis (AD) (Table 1). Although originally thought to be an ILC2-like population, multipotent progenitor type 2 (MPP ${ }^{\text {type2 }}$ ) cells, also shown to be critical for promoting type 2 cytokine-mediated immunity to helminth infection [15], have been distinguished from ILC2s in that they are optimally elicited by IL-25 rather than IL-33 and exhibit a progenitor phenotype with the ability to differentiate into multiple granulocyte populations. Further, MPPtype2 cells exhibit distinct developmental requirements, altered genome-wide transcriptional profile from ILC2s and undergo extramedullary hematopoiesis [16]. Although it would be predicted that MPPtype2 cells are involved in allergic disease, future studies will be required to define their role in this context. Given that MPPtype2 cells and ILC2s appear to be distinct populations, this review will focus specifically on the biology of ILC2s in the context of allergic inflammation.

Curr Opin Immunol. Author manuscript; available in PMC 2014 December 01. 


\section{Regulation and effector function of ILC2s}

Studies in murine models suggest that ILC2s play protective roles in infection. For example, in the context of helminth infection, ILC2s produce IL-13 that promotes goblet cell mucus secretion and smooth muscle contraction, processes that mediate the expulsion of helminth parasites. In the context of influenza infection, ILC2s were found to be a critical source of the epidermal growth factor receptor (EGFR) ligand amphiregulin (Areg), which mediates respiratory epithelial repair following influenza virus-induced lung injury [5]. In contrast to the protective functions of ILC2s during helminth or influenza virus infection, ILC2s induce pathogenic inflammation in the context of allergic disease. ILC2-derived IL-5, IL-9 and IL-13 promote allergic inflammation at barrier surfaces and are associated with the development of asthma-associated airway hyperreactivity (AHR), allergic rhinitis, AD and food allergy (Table 1 and Fig. 1). The production of IL-4 was described only recently in human nasal polyp and murine lung ILC2 populations [17,18]. The precise effector function of IL-4 in the context of ILC2s remains to be determined.

The regulation of ILC2s appears to involve a complex network of signals at the epithelial barrier surface that results in their activation and acquisition of effector functions. ILC2s are elicited by pathogens such as helminth parasites, viruses and fungi as well as allergens, and are activated by the epithelial cell-derived cytokines IL-25, IL-33 and thymic stromal lymphopoietin (TSLP) [11,19]. ILC2s are also activated by IL-2 and express the receptor for IL-7, indicating that they also respond to other stromal and hematopoietic cell-derived cytokines [20]. Beyond cytokine signals, ILC2s have recently been shown respond directly to eicosanoids associated with the pathogenesis of asthma. Specifically, ILC2s are activated by prostaglandin $\mathrm{D}_{2}\left(\mathrm{PGD}_{2}\right)$ [21] and leukotriene $\mathrm{D}_{4}\left(\mathrm{LTD}_{4}\right)$ [18] and are inhibited by lipoxin $\mathrm{A}_{4}\left(\mathrm{LXA}_{4}\right)$ [21] (Fig. 1). Although asthma-associated eicosanoids appear to influence ILC2 function, how cytokine- or tissue-specific signals may regulate the functional and anatomic specialization of ILC2s remains unclear.

\section{ILC2s and asthma}

Although originally identified in the intestine and fat-associated lymphoid clusters [12-14], lineage (Lin)-negative CD $25^{+} \mathrm{CD} 90^{+} \mathrm{IL}-33 \mathrm{R}^{+}$ILC2s in the lung were first described in murine models of influenza, where they were found to exhibit both protective [5] and pathogenic [22] roles in response to virus-induced lung inflammation. Subsequently, IL-33induced ILC2s that produced IL-13 were shown to contribute to the development of AHR in multiple murine asthma models in the absence of $\mathrm{CD}^{+} \mathrm{T}$ cells [23-27]. Similarly, in models of allergen-induced airway inflammation, it was demonstrated that IL-25-, IL-33and TSLP-responsive ILC2s were critical to the development of allergic airway inflammation in lymphocyte-deficient mice $[7,28,29]$. While all of these studies demonstrated that lung-resident ILC2s produce IL-5 and IL-13 effector cytokines, Stockinger and colleagues further demonstrated a critical role for IL-9 in the context of papain-induced lung inflammation. Induction of allergic inflammation in IL-9 reporter mice revealed that ILC2s also express IL-9 in an IL-2-dependent manner, which played a critical role in promoting the survival of ILC2s and in the induction of IL-5 and IL-13 expression (Table 1) [30]. 
Multiple studies indicate that IL-33 is the most significant activator of IL-13-producing ILC2s in allergic inflammation [17,24-26,31,32], but recent reports suggest that other factors, such as eicosanoids, could also play a key role in promoting ILC2 responses in the context of allergic airway inflammation. A recent study has shown that lung ILC2s express the receptor for $\mathrm{LTD}_{4}$, and ligation of this receptor rapidly induces IL-5 production by ILC2s. This process is abrogated by montelukast, a leukotriene receptor antagonist used in the treatment of asthma [18]. In the same study, $\mathrm{LTD}_{4}$ but not IL-33 induced high levels of IL-4 production by ILC2s [18]. Collectively, these studies demonstrated that lung-resident ILC2s are activated by epithelial cell-derived cytokines and leukotrienes and promote allergic inflammation in the lung in multiple model systems (Table 1). However, many outstanding questions remain regarding the regulation and inhibition of ILC2 responses in allergic airway inflammation and the mechanisms by which these cells migrate into and out of lung tissue.

In humans, $\mathrm{Lin}^{-} \mathrm{CD} 127^{+} \mathrm{CRTH} 2^{+}$and $\mathrm{Lin}^{-} \mathrm{CD} 127^{+} \mathrm{CD} 25^{+} \mathrm{CD} 90^{+} \mathrm{IL}_{-} 33 \mathrm{R}^{+}$lung $\mathrm{ILC} 2 \mathrm{~s}$ were first identified in healthy fetal and adult lung tissue by flow cyotmetry $[5,33]$ and subsequently visualized by immunofluorescence as $\mathrm{Lin}^{-} \mathrm{c}-\mathrm{Kit}^{+} \mathrm{CD} 161^{+}$cells [21].

Although ILC2s have not been shown to be enriched to date in disease, elevated expression of IL-25, IL-33 and TSLP has been demonstrated in human asthmatic lung tissue [34-36]. Further, human peripheral blood ILC2s respond to asthma-associated prostaglandin $\mathrm{D}_{2}$ $\left(\mathrm{PGD}_{2}\right)$ by producing IL-13, and this process is inhibited by another molecule called lipoxin $\mathrm{A}_{4}\left(\mathrm{LXA}_{4}\right)[21]$. The studies described above, in which pathogenic $\mathrm{LTD}_{4}$-initiated murine lung ILC2 responses were abrogated following treatment with montelukast, indicate that ILC2s may be a relevant target in the treatment of asthma in patients (Table 1) [18]. Further studies in human subjects will be required to determine whether ILC2s are pathogenic in human asthma and whether these cells could be targeted therapeutically.

\section{Chronic rhinosinusitis}

Chronic rhinosinusitis (CRS) is a common complication arising from allergic rhinitis and, when associated with nasal polyps, is strongly associated with type 2 cytokine production in the nasal mucosa. CRS was the first human disease in which an accumulation of $\mathrm{Lin}^{-}$ CRTH2 ${ }^{+} \mathrm{CD} 161^{+}$ILC2s in inflamed tissue was clearly shown[33]. ILC2s in nasal polyps of CRS patients were originally identified as being responsive to IL-25- and IL-33, and subsequently shown to also respond to TSLP [17]. These studies highlighted that human ILC2s produce IL-4, IL-5, IL-9 and IL-13, and express the TSLP receptor (TSLPR) [17]. A recent study confirmed that ILC2s are enriched in ethmoid sinus mucosa of patients with CRS and nasal polyps in comparison to control CRS patients without nasal polyps [32]. This study also demonstrated that the ILC2s from CRS patients responded to IL-33-mediated stimulation by producing IL-13 [32], further suggesting that ILC2s may contribute to the pathogenesis of allergic upper airway disease in humans. Consistent with findings in prior studies [17], TSLP has recently been shown to be highly expressed in the nasal polyps of CRS patients (Table 1) [37]. Although IL-33 appears to be more potent than TSLP in activating type 2 cytokine production from nasal polyp ILC2s [17], further studies will be required to determine which cytokines optimally promote ILC2-mediated inflammation in 
CRS and whether these cells have a causal role in the development of nasal polyps or pathology in CRS patients.

\section{Atopic dermatitis}

Lesional human AD skin has been demonstrated to have elevated expression of IL-25, IL-33

and TSLP [38-41]. Additionally, ILC2s have been identified in both murine and human skin and are enriched in the lesional skin of human AD patients [20,23]. Although IL-33 has emerged as the dominant cytokine in the activation of ILC2s from murine lung [42], human blood and nasal polyps [17], skin ILC2s were found to be IL-33- and IL-25-independent but dependent on TSLP for their elicitation during murine AD-like disease [43]. Further, skinassociated ILC2s could directly induce AD-like pathology and $\mathrm{T}_{\mathrm{H}} 2$ cell responses in vivo [43]. In a subsequent study, intravital multiphoton microscopy was employed to visualize interactions between skin-resident ILC2s and mast cells [20]. Further, skin ILC2s were found to constitutively express IL-13 and produce IL-5 in response to IL-2-mediated activation [20]. Collectively, these studies demonstrate that skin ILC2s promote type 2 cytokine-associated skin inflammation and coordinately interact with other innate and adaptive cells in the skin to influence their function (Table 1). The unique dependence of skin ILC2s on TSLP suggests that there may be additional differences in the regulation of skin-resident ILC2 responses, but further studies will be required to fully assess the factors that promote and regulate ILC2-mediated skin inflammation.

\section{Food allergy}

ILC2s were originally identified in gastrointestinal tissue and found to promote antihelminth immunity in the gut [12-14]. These studies identified that IL-25- and IL-33responsive ILC2s were critical for the development of type 2 cytokine-associated inflammation and goblet cell hyperplasia that facilitate expulsion of Nippostrongylus brasiliensis in the absence of adaptive immunity [12-14]. A more recent study has shown that IL-33 is critical for the induction of IL-13 production by ILC2s to mediate worm expulsion [31]. A murine model of oxazalone-induced colitis demonstrated that ILC2s promote gut inflammation in an IL-25-dependent fashion [44]. In the context of food allergy, elevated IL-25, IL-33 and TSLP responses have been observed in murine models and in patients [45-47]. Taken together, these studies provoke the hypothesis that ILC2s may promote gut inflammation in the context of food allergy through the expression of the type 2 cytokines IL-4, IL-5 and IL-13. However, the specific role of ILC2s in murine models of food allergy remains to be examined. In addition, although ILC2s have been characterized in human fetal gut and in the gut of healthy subjects as well as patients with inflammatory bowel disease, enrichment and accumulation of these populations has not been demonstrated in inflamed human intestinal tissue [33], suggesting that further studies will be required to elucidate the role of ILC2s in promoting intestinal allergic inflammation in humans (Table 1). 


\section{Conclusions and future directions}

Originally described in the context of anti-helminth immunity, ILC2s appear to play a variety of roles at multiple barrier surfaces including the upper and lower airways, skin and gut [48]. However, there are a number of questions that remain regarding the function of ILC2s. For example, the potential tissue-specific factors that regulate ILC2s remain poorly understood. The body of evidence suggests that IL-33 may be the dominant cytokine for the activation of lung and airway ILC2s $[17,19,42]$, while IL-25 is critical for their elicitation in gut inflammation [44]. In the skin, ILC2s appear to be predominantly regulated by TSLP in the context of AD-like disease [43]. Collectively, whether IL-25, IL-33 or TSLP is the dominant cytokine for the activation and/or elicitation of ILC2s at different barrier surfaces remains to be fully determined. Additionally, recent studies have shown that ILC2s interact with other innate cell populations such as mast cells[20] and that ILC2s can influence $\mathrm{T}_{\mathrm{H}} 2$ cell responses [43]. In this context, another recent study has identified that group 3 ILCs (ILC3s) in the gut regulate $\mathrm{CD} 4^{+} \mathrm{T}$ cell responses to commensal bacteria via MHC II expression [49], and MHC II expression has been previously demonstrated on ILC2s [13]. Thus, understanding how ILC2s may coordinately promote or regulate type 2 cytokineassociated inflammation through interactions with various innate and adaptive cell populations remains to be further explored. Moreover, the role that ILC2s play in food allergy and other allergic diseases such as urticaria, eosinophilic gastrointestinal diseases, and anaphylaxis remains entirely unexplored. Finally, future studies aimed at better understanding the regulation and effector mechanisms of human ILC2s will be critical to developing therapeutics that target ILC2s to treat allergic disease.

\section{References}

1. Spits H, Artis D, Colonna M, Diefenbach A, Di Santo JP, Eberl G, Koyasu S, Locksley RM, McKenzie AN, Mebius RE, et al. Innate lymphoid cells--a proposal for uniform nomenclature. Nat Rev Immunol. 2013; 13:145-149. [PubMed: 23348417]

2. Bjorkstrom NK, Kekalainen E, Mjosberg J. Tissue-specific effector functions of innate lymphoid cells. Immunology. 2013

3. Yokota Y, Mansouri A, Mori S, Sugawara S, Adachi S, Nishikawa S, Gruss P. Development of peripheral lymphoid organs and natural killer cells depends on the helix-loop-helix inhibitor Id2 Nature. 1999; 397:702-706. [PubMed: 10067894]

4. Satoh-Takayama N, Lesjean-Pottier S, Vieira P, Sawa S, Eberl G, Vosshenrich CA, Di Santo JP. IL-7 and IL-15 independently program the differentiation of intestinal CD3-NKp46+ cell subsets from Id2-dependent precursors. J Exp Med. 2010; 207:273-280. [PubMed: 20142427]

5. Monticelli LA, Sonnenberg GF, Abt MC, Alenghat T, Ziegler CG, Doering TA, Angelosanto JM, Laidlaw BJ, Yang CY, Sathaliyawala T, et al. Innate lymphoid cells promote lung-tissue homeostasis after infection with influenza virus. Nat Immunol. 2011; 12:1045-1054. [PubMed: 21946417]

6. Wong SH, Walker JA, Jolin HE, Drynan LF, Hams E, Camelo A, Barlow JL, Neill DR, Panova V, Koch U, et al. Transcription factor RORalpha is critical for nuocyte development. Nat Immunol. 2012; 13:229-236. [PubMed: 22267218] . **This paper was the first study to demonstrate that $\mathrm{RORa}$ is an essential transcription factor for the development of ILC2s.

7. Halim TY, MacLaren A, Romanish MT, Gold MJ, McNagny KM, Takei F. Retinoic-acid-receptorrelated orphan nuclear receptor alpha is required for natural helper cell development and allergic inflammation. Immunity. 2012; 37:463-474. [PubMed: 22981535] . *This paper was one of the first studies to demonstrate that RORa is an essential transcription factor for the development of ILC2s. 
8. Hoyler T, Klose CS, Souabni A, Turqueti-Neves A, Pfeifer D, Rawlins EL, Voehringer D, Busslinger M, Diefenbach A. The transcription factor GATA-3 controls cell fate and maintenance of type 2 innate lymphoid cells. Immunity. 2012; 37:634-648. [PubMed: 23063333] . **This paper demonstrated that GATA-3 is an essential transcription factor for the development of ILC2s.

9. Klein Wolterink RG, Serafini N, van Nimwegen M, Vosshenrich CA, de Bruijn MJ, Fonseca Pereira D, Veiga Fernandes H, Hendriks RW, Di Santo JP. Essential, dose-dependent role for the transcription factor Gata3 in the development of IL-5+ and IL-13+ type 2 innate lymphoid cells. Proc Natl Acad Sci U S A. 2013; 110:10240-10245. [PubMed: 23733962]

10. Yang Q, Monticelli LA, Saenz SA, Chi AW, Sonnenberg GF, Tang J, De Obaldia ME, Bailis W, Bryson JL, Toscano K, et al. T cell factor 1 is required for group 2 innate lymphoid cell generation. Immunity. 2013; 38:694-704. [PubMed: 23601684] . **This paper demonstrated that TCF1 is an essential transcription factor for the development of ILC2s.

11. Sonnenberg GF, Artis D. Innate lymphoid cell interactions with microbiota: implications for intestinal health and disease. Immunity. 2012; 37:601-610. [PubMed: 23084357]

12. Moro K, Yamada T, Tanabe M, Takeuchi T, Ikawa T, Kawamoto H, Furusawa J, Ohtani M, Fujii $\mathrm{H}$, Koyasu S. Innate production of $\mathrm{T}(\mathrm{H}) 2$ cytokines by adipose tissue-associated c-Kit(+)Sca-1(+) lymphoid cells. Nature. 2010; 463:540-544. [PubMed: 20023630]

13. Neill DR, Wong SH, Bellosi A, Flynn RJ, Daly M, Langford TK, Bucks C, Kane CM, Fallon PG, Pannell R, et al. Nuocytes represent a new innate effector leukocyte that mediates type-2 immunity. Nature. 2010; 464:1367-1370. [PubMed: 20200518]

14. Price AE, Liang HE, Sullivan BM, Reinhardt RL, Eisley CJ, Erle DJ, Locksley RM. Systemically dispersed innate IL-13-expressing cells in type 2 immunity. Proceedings of the National Academy of Sciences of the United States of America. 2010; 107:11489-11494. [PubMed: 20534524]

15. Saenz SA, Siracusa MC, Perrigoue JG, Spencer SP, Urban JF Jr, Tocker JE, Budelsky AL, Kleinschek MA, Kastelein RA, Kambayashi T, et al. IL25 elicits a multipotent progenitor cell population that promotes $\mathrm{T}(\mathrm{H}) 2$ cytokine responses. Nature. 2010; 464:1362-1366. [PubMed: 20200520]

16. Saenz SA, Siracusa MC, Monticelli LA, Ziegler CG, Kim BS, Brestoff JR, Peterson LW, Wherry EJ, Goldrath AW, Bhandoola A, et al. IL-25 simultaneously elicits distinct populations of innate lymphoid cells and multi-potent progenitor type 2 (MPP ${ }^{\text {type2 }}$ ) cells. J Exp Med. 2013 (In Press). . *This paper demonstrated that IL-25 has differential effects on ILC2s and MPP ${ }^{t y p e} 2$ cells, indicating that these are distinct innate cell populations.

17. Mjosberg J, Bernink J, Golebski K, Karrich JJ, Peters CP, Blom B, te Velde AA, Fokkens WJ, van Drunen CM, Spits H. The transcription factor GATA3 is essential for the function of human type 2 innate lymphoid cells. Immunity. 2012; 37:649-659. [PubMed: 23063330] . **This paper demonstrated that GATA3, regulated by TSLP, is an essential transcription factor for the function of human ILC2s in the context of chronic rhinosinusitis.

18. Doherty TA, Khorram N, Lund S, Mehta AK, Croft M, Broide DH. Lung type 2 innate lymphoid cells express cysteinyl leukotriene receptor 1 , which regulates $\mathrm{T} 2$ cytokine production. The Journal of Allergy and Clinical Immunology. 2013. *This paper demonstrated that ILC2s can be activated by leukotriene $\mathrm{D} 4$.

19. Monticelli LA, Sonnenberg GF, Artis D. Innate lymphoid cells: critical regulators of allergic inflammation and tissue repair in the lung. Current Opinion in Immunology. 2012; 24:284-289. [PubMed: 22521139]

20. Roediger B, Kyle R, Yip KH, Sumaria N, Guy TV, Kim BS, Mitchell AJ, Tay SS, Jain R, ForbesBlom E, et al. Cutaneous immunosurveillance and regulation of inflammation by group 2 innate lymphoid cells. Nature Immunology. 2013; 14:564-573. [PubMed: 23603794] . **This paper was the first to employ two-photon intravital microscopy to visualize ILC2s in vivo.

21. Barnig C, Cernadas M, Dutile S, Liu X, Perrella MA, Kazani S, Wechsler ME, Israel E, Levy BD. Lipoxin A4 regulates natural killer cell and type 2 innate lymphoid cell activation in asthma. Science Translational Medicine. 2013; 5:174ra126.

22. Chang YJ, Kim HY, Albacker LA, Baumgarth N, McKenzie AN, Smith DE, Dekruyff RH, Umetsu DT. Innate lymphoid cells mediate influenza-induced airway hyper-reactivity independently of adaptive immunity. Nat Immunol. 2011; 12:631-638. [PubMed: 21623379] 
23. Kim HY, Chang YJ, Subramanian S, Lee HH, Albacker LA, Matangkasombut P, Savage PB, McKenzie AN, Smith DE, Rottman JB, et al. Innate lymphoid cells responding to IL-33 mediate airway hyperreactivity independently of adaptive immunity. J Allergy Clin Immunol. 2012; 129:216-227. e211-e216. [PubMed: 22119406]

24. Bartemes KR, Iijima K, Kobayashi T, Kephart GM, McKenzie AN, Kita H. IL-33-responsive lineage- CD25+CD44(hi) lymphoid cells mediate innate type 2 immunity and allergic inflammation in the lungs. J Immunol. 2012; 188:1503-1513. [PubMed: 22198948] . **This paper was the first to implicate ILC2s in the pathogeneis of allergic airway disease.

25. Beamer CA, Girtsman TA, Seaver BP, Finsaas KJ, Migliaccio CT, Perry VK, Rottman JB, Smith DE, Holian A. IL-33 mediates multi-walled carbon nanotube (MWCNT)-induced airway hyperreactivity via the mobilization of innate helper cells in the lung. Nanotoxicology. 2012

26. Salmond RJ, Mirchandani AS, Besnard AG, Bain CC, Thomson NC, Liew FY. IL-33 induces innate lymphoid cell-mediated airway inflammation by activating mammalian target of rapamycin. J Allergy Clin Immunol. 2012; 130:1159-1166. e1156. [PubMed: 22738676]

27. Doherty TA, Khorram N, Chang JE, Kim HK, Rosenthal P, Croft M, Broide DH. STAT6 regulates natural helper cell proliferation during lung inflammation initiated by Alternaria. American journal of physiology. Lung Cellular and Molecular Physiology. 2012; 303:L577-L588. [PubMed: 22865552]

28. Halim TY, Krauss RH, Sun AC, Takei F. Lung natural helper cells are a critical source of Th2 celltype cytokines in protease allergen-induced airway inflammation. Immunity. 2012; 36:451-463. [PubMed: 22425247] . *This paper was one of the first to dentify that TSLP can activate ILC2s in vitro.

29. Klein Wolterink RG, Kleinjan A, van Nimwegen M, Bergen I, de Bruijn M, Levani Y, Hendriks RW. Pulmonary innate lymphoid cells are major producers of IL-5 and IL-13 in murine models of allergic asthma. Eur J Immunol. 2012; 42:1106-1116. [PubMed: 22539286]

30. Wilhelm C, Hirota K, Stieglitz B, Van Snick J, Tolaini M, Lahl K, Sparwasser T, Helmby H, Stockinger B. An IL-9 fate reporter demonstrates the induction of an innate IL-9 response in lung inflammation. Nat Immunol. 2011; 12:1071-1077. [PubMed: 21983833]

31. Hung LY, Lewkowich IP, Dawson LA, Downey J, Yang Y, Smith DE, Herbert DR. IL-33 drives biphasic IL-13 production for noncanonical Type 2 immunity against hookworms. Proceedings of the National Academy of Sciences of the United States of America. 2013; 110:282-287. [PubMed: 23248269]

32. Shaw JL, Fakhri S, Citardi MJ, Porter PC, Corry DB, Kheradmand F, Liu YJ, Luong A. IL-33Responsive Innate Lymphoid Cells are an Important Source of IL-13 in Chronic Rhinosinusitis with Nasal Polyps. American journal of respiratory and critical care medicine. 2013

33. Mjosberg JM, Trifari S, Crellin NK, Peters CP, van Drunen CM, Piet B, Fokkens WJ, Cupedo T, Spits H. Human IL-25- and IL-33-responsive type 2 innate lymphoid cells are defined by expression of CRTH2 and CD161. Nature immunology. 2011; 12:1055-1062. [PubMed: 21909091]

34. Prefontaine D, Nadigel J, Chouiali F, Audusseau S, Semlali A, Chakir J, Martin JG, Hamid Q. Increased IL-33 expression by epithelial cells in bronchial asthma. The Journal of Allergy and Clinical Immunology. 2010; 125:752-754. [PubMed: 20153038]

35. Corrigan CJ, Wang W, Meng Q, Fang C, Eid G, Caballero MR, Lv Z, An Y, Wang YH, Liu YJ, et al. Allergen-induced expression of IL-25 and IL-25 receptor in atopic asthmatic airways and latephase cutaneous responses. The Journal of Allergy and Clinical Immunology. 2011; 128:116-124. [PubMed: 21570719]

36. Shikotra A, Choy DF, Ohri CM, Doran E, Butler C, Hargadon B, Shelley M, Abbas AR, Austin $\mathrm{CD}$, Jackman $\mathrm{J}$, et al. Increased expression of immunoreactive thymic stromal lymphopoietin in patients with severe asthma. The Journal of Allergy and Clinical Immunology. 2012; 129:104111. e101-e109. [PubMed: 21975173]

37. Nagarkar DR, Poposki JA, Tan BK, Comeau MR, Peters AT, Hulse KE, Suh LA, Norton J, Harris $\mathrm{KE}$, Grammer LC, et al. Thymic stromal lymphopoietin activity is increased in nasal polyps of patients with chronic rhinosinusitis. The Journal of Allergy and Clinical Immunology. 2013 
38. Soumelis V, Reche PA, Kanzler H, Yuan W, Edward G, Homey B, Gilliet M, Ho S, Antonenko S, Lauerma A, et al. Human epithelial cells trigger dendritic cell mediated allergic inflammation by producing TSLP. Nature Immunology. 2002; 3:673-680. [PubMed: 12055625]

39. Deleuran M, Hvid M, Kemp K, Christensen GB, Deleuran B, Vestergaard C. IL-25 induces both inflammation and skin barrier dysfunction in atopic dermatitis. Chemical Immunology and Allergy. 2012; 96:45-49. [PubMed: 22433370]

40. Hvid M, Vestergaard C, Kemp K, Christensen GB, Deleuran B, Deleuran M. IL-25 in atopic dermatitis: a possible link between inflammation and skin barrier dysfunction? The Journal of Investigative Dermatology. 2011; 131:150-157. [PubMed: 20861853]

41. Savinko T, Matikainen S, Saarialho-Kere U, Lehto M, Wang G, Lehtimaki S, Karisola P, Reunala T, Wolff H, Lauerma A, et al. IL-33 and ST2 in atopic dermatitis: expression profiles and modulation by triggering factors. The Journal of Investigative Dermatology. 2012; 132:13921400. [PubMed: 22277940]

42. Barlow JL, Peel S, Fox J, Panova V, Hardman CS, Camelo A, Bucks C, Wu X, Kane CM, Neill $\mathrm{DR}$, et al. IL-33 is more potent than IL-25 in provoking IL-13-producing nuocytes (type 2 innate lymphoid cells) and airway contraction. The Journal of Allergy and Clinical Immunology. 2013. *This paper demonstrated that IL-33 is a more potent activator of ILC2s in the airway than IL-25.

43. Kim BS, Siracusa MC, Saenz SA, Noti M, Monticelli LA, Sonnenberg GF, Hepworth MR, Van Voorhees AS, Comeau MR, Artis D. TSLP elicits IL-33-independent innate lymphoid cell responses to promote skin inflammation. Science Translational Medicine. 2013; 5:170ra116. **This paper represents the first identification of ILC2s in both human and murine skin and their role in atopic dermatitis.

44. Camelo A, Barlow JL, Drynan LF, Neill DR, Ballantyne SJ, Wong SH, Pannell R, Gao W, Wrigley K, Sprenkle J, et al. Blocking IL-25 signalling protects against gut inflammation in a type-2 model of colitis by suppressing nuocyte and NKT derived IL-13. J Gastroenterol. 2012; 47:1198-1211. [PubMed: 22539101]

45. Chu DK, Llop-Guevara A, Walker TD, Flader K, Goncharova S, Boudreau JE, Moore CL, Seunghyun In T, Waserman S, Coyle AJ, et al. IL-33, but not thymic stromal lymphopoietin or IL-25, is central to mite and peanut allergic sensitization. The Journal of Allergy and Clinical Immunology. 2013; 131:187-200. e181-e188. [PubMed: 23006545]

46. Blazquez AB, Mayer L, Berin MC. Thymic stromal lymphopoietin is required for gastrointestinal allergy but not oral tolerance. Gastroenterology. 2010; 139:1301-1309. [PubMed: 20600023]

47. Herberth G, Daegelmann C, Roder S, Behrendt H, Kramer U, Borte M, Heinrich J, Herbarth O, Lehmann I. IL-17E but not IL-17A is associated with allergic sensitization: results from the LISA study. Pediatric allergy and immunology : official publication of the European Society of Pediatric Allergy and Immunology. 2010; 21:1086-1090. [PubMed: 20492545]

48. Tait Wojno ED, Artis D. Innate lymphoid cells: balancing immunity, inflammation, and tissue repair in the intestine. Cell host \& microbe. 2012; 12:445-457. [PubMed: 23084914]

49. Hepworth MR, Monticelli LA, Fung TC, Ziegler CG, Grunberg S, Sinha R, Mantegazza AR, Ma HL, Crawford A, Angelosanto JM, et al. Innate lymphoid cells regulate CD4+ T-cell responses to intestinal commensal bacteria. Nature. 2013; 498:113-117. [PubMed: 23698371] 


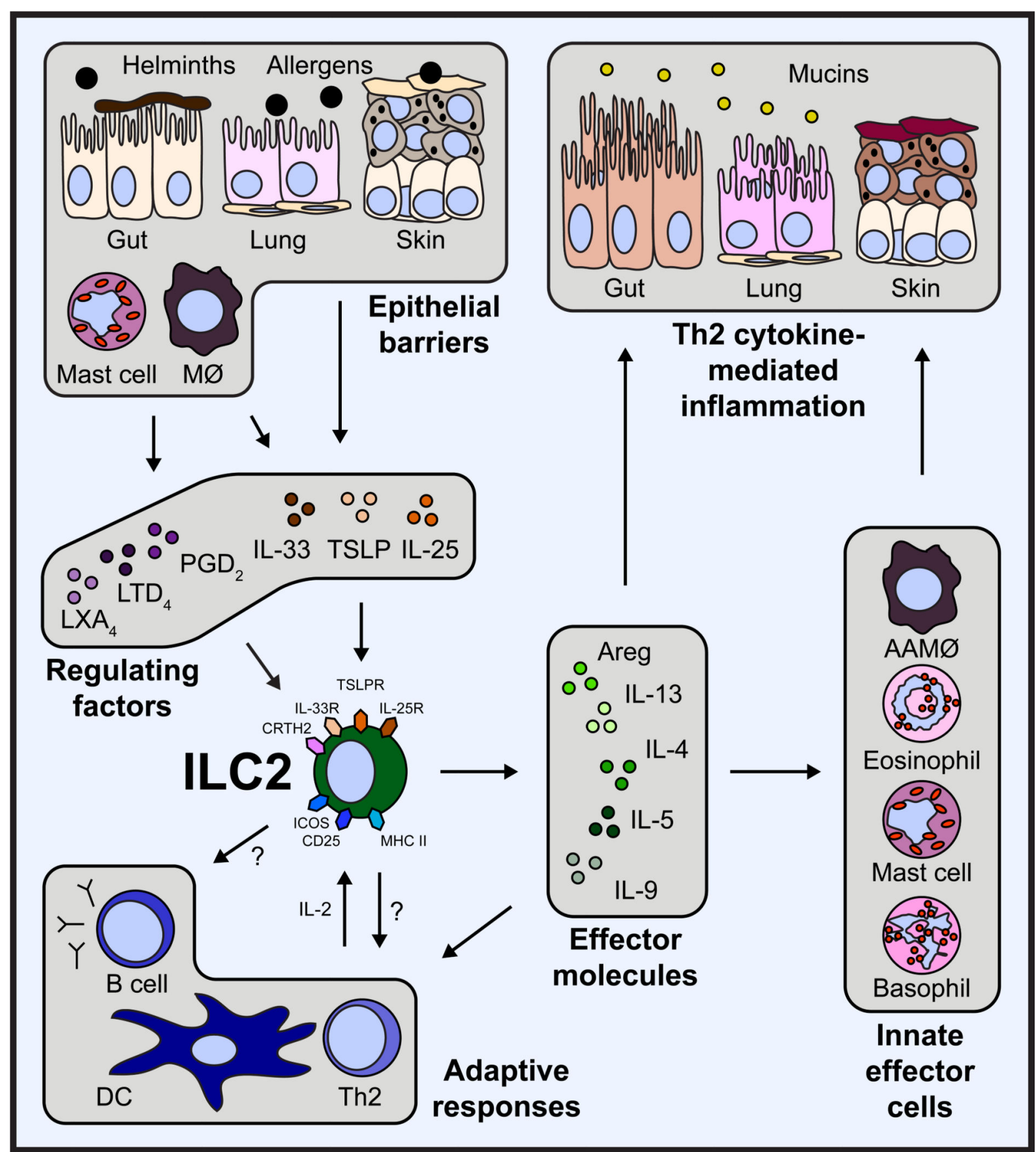

Figure 1. ILC2s influence the development of Th2 cytokine-mediated inflammation through multiple pathways

In response to helminth parasites or allergens, epithelial cells, macrophages, and mast cells at multiple barrier surfaces, including the gut, lung and skin, produce the cytokines IL-25, IL-33 and TSLP or eicosanoids that regulate the accumulation and activation of ILC2s. Activated ILC2s produce effector molecules such as amphiregulin (Areg), IL-4, IL-5, IL-9 and IL-13. These factors influence the responses and cytokine production of innate effector cells, including alternatively activated macrophages (AAM $\varnothing$ ), eosinophils, mast cells and 
basophils. In addition, ILC2s influence adaptive responses through production of effector molecules, and potentially interact with B cells and T cells through expression of ICOS or MHC II, respectively. Together, ILC2-derived effector molecules and the influence of ILC2s on other innate and adaptive immune cells contribute to the development of type 2 cytokine-mediated inflammation in the gut, lung and skin. 
光.

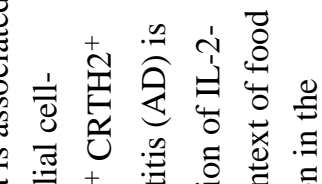

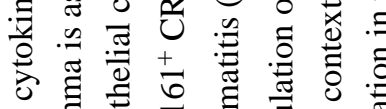

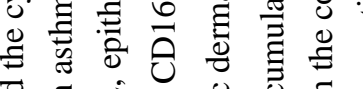

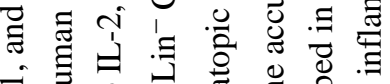

苟焉

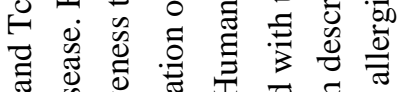

ఫิ : :

䒕 สี

ชิ

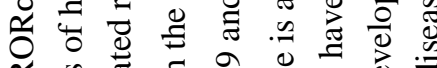

ฯ

ปี

की

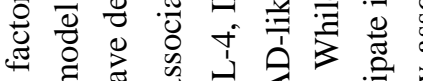

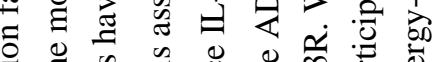

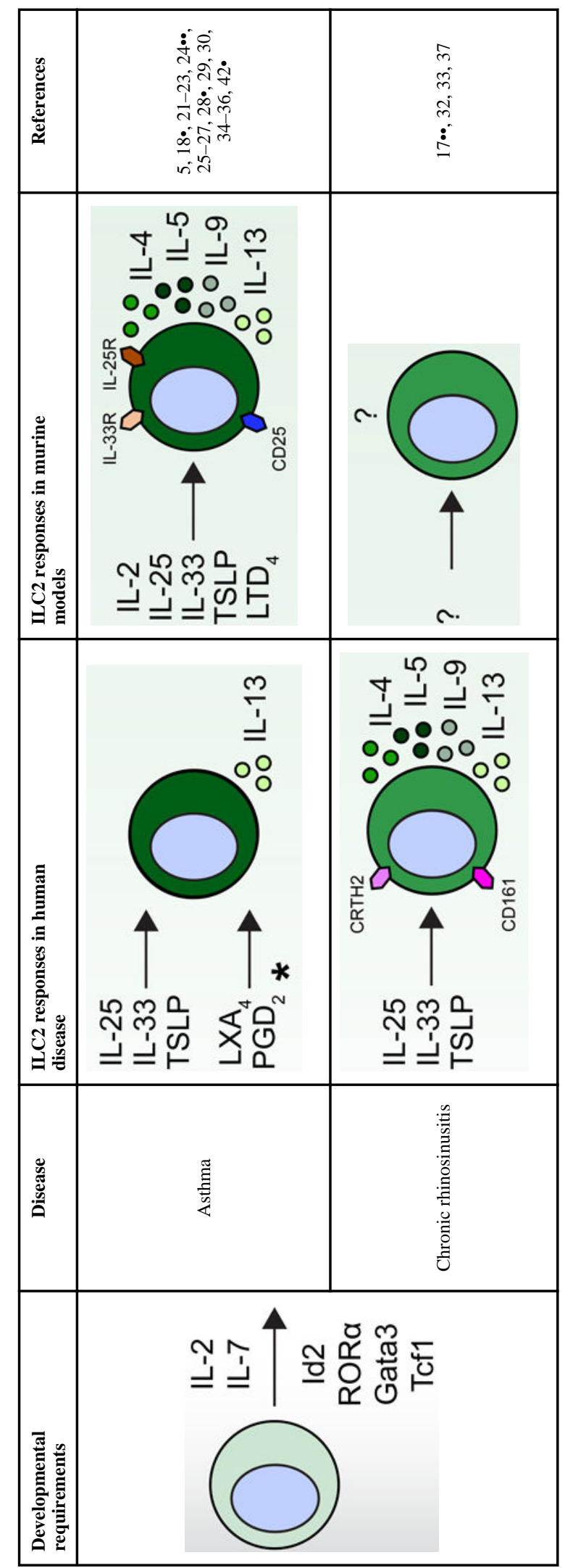




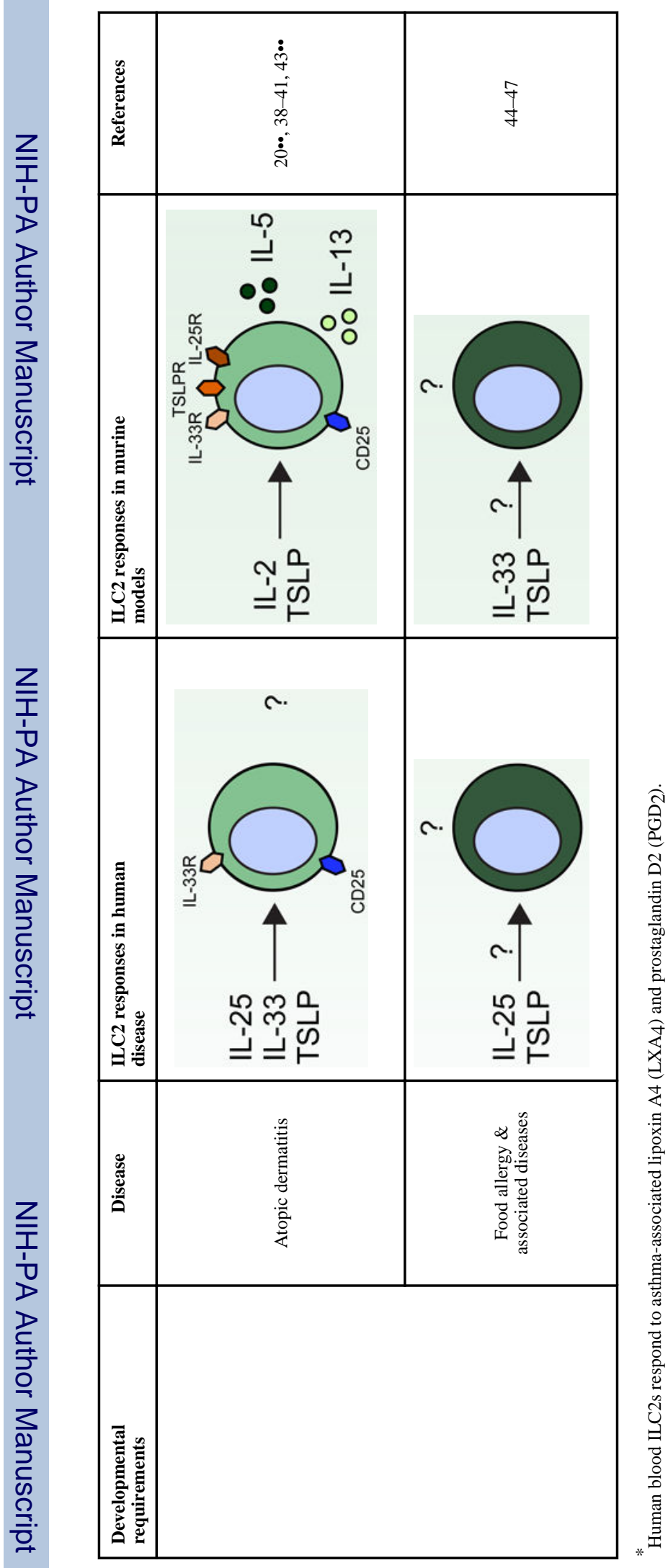

Curr Opin Immunol. Author manuscript; available in PMC 2014 December 01. 